\title{
The Research of Experiential Learning to Enhance Ocean Stewardship and Pro-Environmental Behavior Intention-Cross-Cultural Comparison from Taiwan and Indonesia
}

\author{
Chia Dai (Ray) Yen ${ }^{*}$, Julia Veranita Sembiring2 \\ ${ }^{1}$ Graduate Institute of Education, National Taiwan Ocean University, Taiwan \\ ${ }^{2}$ Teacher, SMP Negeri 2 Satu Atap Batang Serangan, North Sumatera, Indonesia \\ Email: ^hamrater@msn.com, juliaveranitasembiring@gmail.com
}

How to cite this paper: Yen, C. D. (Ray), \& Sembiring, J. V. (2020). The Research of Experiential Learning to Enhance Ocean Stewardship and Pro-Environmental Behavior Intention-Cross-Cultural Comparison from Taiwan and Indonesia. Creative Education, 11, 1008-1025.

https://doi.org/10.4236/ce.2020.117073

Received: June 22, 2020

Accepted: July 10, 2020

Published: July 13, 2020

Copyright () 2020 by author(s) and Scientific Research Publishing Inc. This work is licensed under the Creative Commons Attribution International License (CC BY 4.0).

http://creativecommons.org/licenses/by/4.0/

(c) (i) Open Access

\begin{abstract}
Marine education is a critical way to stop global marine problems. Educators are focus on educating people with not only attitude but also positive behavior toward the world. The motivation of this research is to explain the experiential learning approaches, ocean stewardship, and people's pro-environmental behavior intention to their environment. This research used a survey method to collect data from Indonesia and Taiwan. There are 377 of participants from Taiwan and 390 of participants from Indonesia. The result shows that experiential learning is positively related to pro-environmental behavior intention. Experiential learning, ocean stewardship, and pro-environmental behavior intention are positively related to both Taiwanese and Indonesian students. However, the role of ocean stewardship between experiential learning and pro-environmental behavior intention relationship is full mediation in Indonesia, but the Taiwan sample is partially mediate. The results provide a cross-nation comparison to understand the way of promoting marine education through experiential learning and ocean stewardship. The moderation effects show that the relationship of ocean stewardship to pro-environmental behavior intention in Taiwan is higher than Indonesia, and the relationship of experiential learning to pro-environmental behavior intention in Taiwan is lower than Indonesia.
\end{abstract}




\section{Keywords}

Experiential Learning, Ocean Stewardship, Pro-Environmental Behavior Intention, Marine Education, Ocean Literacy

\section{Introduction}

The ocean is an essential factor for the earth's ecosystem. It is a crucial component of the hydrologic cycle system and the interactive cycling of water between the sea, continents, and the atmosphere. The ocean covers $70.8 \%$ of the earth's surface, seawater contains $97 \%$ pure water, over $50 \%$ of oxygen comes from the ocean, and seafood supplies worldwide over a quarter of the world protein source et al. Marine science supports much information about the relationship of the ocean and humanity. Scientists also discovered that currents influence the climate and weather patterns (Smith \& Ford, 1995). The ocean is a treasure pool which contains billions of metallic elements, fishery resource, energy, tourism, and sea transportation et al. Global oceanographers, marine biologists, scientists, and marine educators have provided much of our understanding of the ocean. The concept of a world ocean is essential to understanding world ecology and the effect of human activities on the environment. An important concept is "Ocean Literacy." Ocean Literacy is defined as "understand the ocean's influence on you and your influence on the ocean" (NMEA, 2010). The goal of marine education not only educates students and citizens to understand the ocean scientifically but also to encourage students to display dynamic behaviors to care about the ocean environment (Greely, 2008).

Human activities in our daily life cause many environmental problems (Dunlap, Van Liere, Mertig, \& Jones, 2000). Human activities have a direct and indirect effect on the earth's system. For example, in 2007, 287 million tons of plastics were produced worldwide, with annual growth of about $3 \%$ in the US, production since 1980 (Fujii, 2006). One of the problems inherent in dumping plastics at sea is that most of the plastic floats, floatation of waste in the sea causes animals of all kinds to die as a result of being tangled in plastic debris and plastics entering the ocean food chain. Environmentalism is an ideology to evoke the responsibility of humans to respect, protect, and preserve the environment. Environmental awareness is an essential part of the movement's success (Stern, Dietz, Abel, Guagnano, \& Kalof, 1999).

Ocean stewardship is acting responsibly to conserve the oceans and their resources for future and present generations (Schlag, 2004). Marine education is also a way of cultivating the concept of ocean stewardship. Furthermore, explain the relationship between marine education practices to attitude and behavior intention is more important for marine education. However, it is a lack of connection between experiential learning and students' ocean stewardship that results in a lack of changed behavior. Therefore, this research intends to research experiential learning to ocean stewardship and pro-environmental behavior intention. 
In turn, the result of the study can contribute an important understanding to improve students' knowledge about the ocean. Besides, Taiwan and Indonesia have similar education systems, but they have different religious and cultural systems, and they are also at the beginning of promoting marine education. The purpose of this research is to clarify the relationship between experiential learning, ocean stewardship, and pro-environmental behavior from Taiwan and Indonesia.

\section{Literature Review}

\subsection{Experiential Learning}

Experiential learning is a simple form of learning skills and ability to be obtained in experiential learning and execute a plan, complete tasks, and have new experiences (Kolb, 1984). Experiential learning can motivate and encourage students to be more active in the learning process, which is capable of changing attitudes and beliefs (Enos, 2012). Experiential learning is a form of apprenticeship, personal, and teaching activities. The Experiential Learning Theory developmental model (Kolb \& Kolb, 2005; Kolb, 2014) defines three stages: 1) acquisition, the growth of necessary abilities and cognitive structures develop; 2) specialization, from early work and personal experiences of adulthood, where social, educational, and organizational socialization forces shape the development specialized learning style; and 3) integration non-dominant modes of learning expressed in work and personal life. The four steps of experiential learning are concrete experience, reflective observation, abstract conceptualization, and active experimentation as Figure 1.

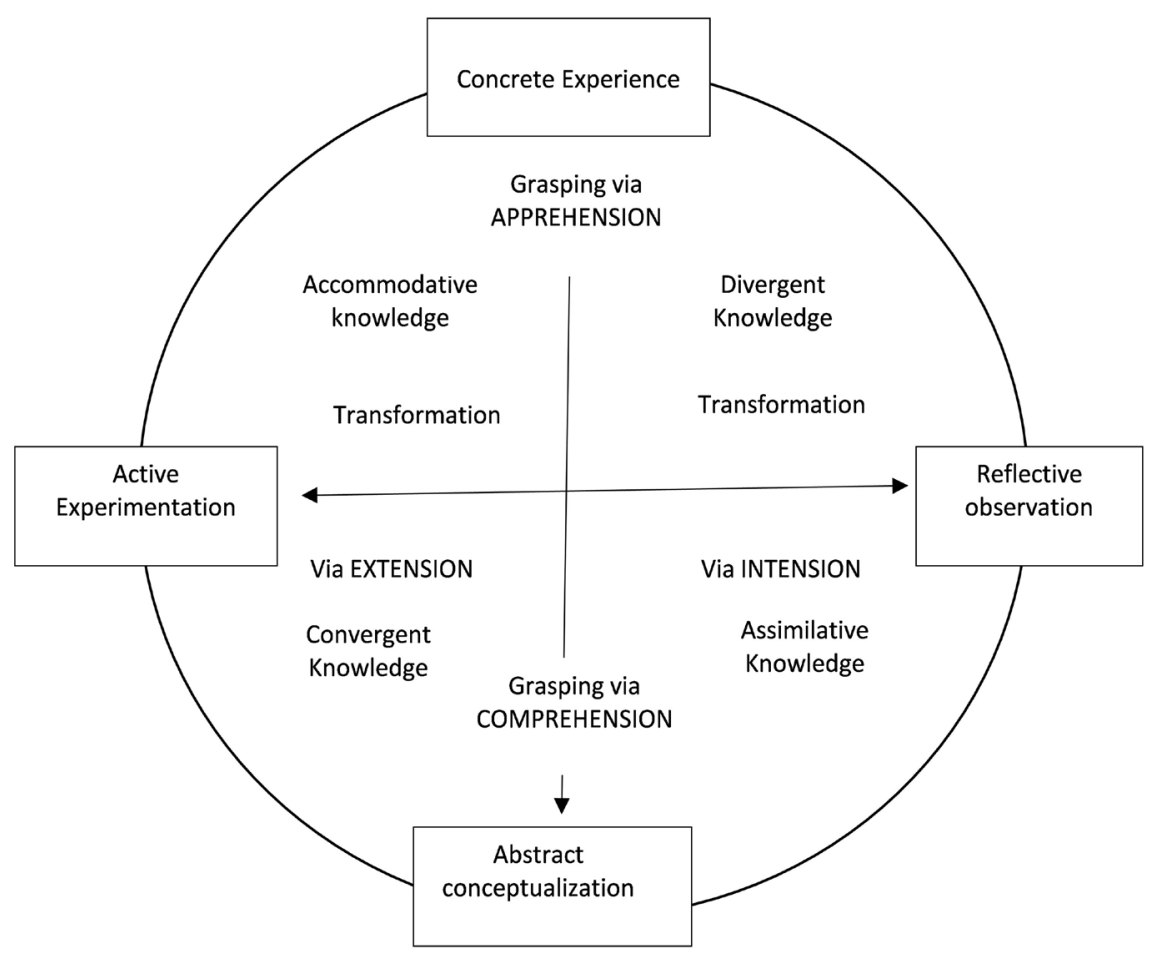

Figure 1. Figure of experiential learning factor by Kolb (1984). 
Students' interest in learning is increasing the transformative sustainability, improving their education, and building up their knowledge base. Still, it also must be supported by critical pedagogy to satisfy the curiosity of students to focus on the lesson that they do (Burns \& Briley, 2015). Guest, Lotze, \& Wallace (2015) indicated the skills and knowledge of students about ocean literacy would increase ocean stewardship students step by step. Researchers summarized the differentiating characteristics of experiential learning as: 1) active rather than passive learning; 2) Student-based rather than teacher-based learning; 3) Subjective experiences and personal growth; 4) Learning through evaluation and reflection; 5) Perception-based rather than theory-based learning; 6) Participative rather than memorization learning; 7) Inductive rather than deductive learning; 8) Exploration invention and application (Kolb, 1984).

\subsection{Ocean Stewardship}

Stewardship is one of the norms that is available to guide ocean governance. Marine education emphasizes that society needs a proactive attitude, comprehensive and participatory to face the sustainability of ocean pollution, decreasing biodiversity, coastal development, and climate change and also need to enhance ocean literacy (Obama, 2010). We also need concern attitude, responsibility, and empowerment to handle and aid the recovery of the damage to the ocean. Formal educational attainment is essential to ocean stewardship because participants require the capacity to understand complex environmental issues, critically analyze problems, and find solutions to these problems (Schlag, 2004). Stewardship is essential for protecting, preserving, and restoring the environment.

Ocean literacy can show up personal knowledge (Steel et al., 2005). The main point of ocean literacy is to provide a positive impact on society's understanding, attitude, and behavior to protect the ocean. Having good knowledge about the ocean will indirectly increase personal stewardship and action to take decision-related marine and environment. However, to apply the ocean stewardship, we must have a balance of perspective.

The New Environment Paradigm (NEP) focuses on the belief of human behavior to damage the environment, existence of social growth, and humans to dominate the biosphere (Stern, Kalof, Dietz, \& Guagnano, 1995). Language, traditional, and cultural skills are essential for ocean stewardship because they encourage youth to complete their education, which will provide them with the knowledge and skills to participate in ocean stewardship effectively. According to Davis (2004), ocean stewardship has four factors that can support it. They are Know, Restore, Protect, and Connect. Daigle (2003) argued concerning the need for greater public involvement in coastal conservation, "the only hope for further progress on environmental protection and sustainable development lies with a public that is not only informed but also engaged." (Carpini \& Keeter, 1996). Van Dover et al. (2014) proposed three directions to advance deep-ocean stewardship: 1) protection and mitigation, 2) research, and 3) collaborative governance. (1) Protection and reduction recognize the high expense and near impos- 
sibility of restoring many deep-ocean ecosystems.

To be adequately protected areas must be multisector in application to avoid damage by one sector when protected by another. The Environmental Studies Program (EPS) design around students to take an active role in the local environment that involved in the cleanup and stewardship projects in the local community to develop an understanding of how natural and human systems interact (Dube, 2009). People who become involved in stewardship activities enjoy benefits. These benefits include learning more about their natural environment, meeting other people with similar interests and values, having fun, and taking pride in having contributed to the well-being of their community and natural environment (Schlag, 2004). Getting involved in ocean stewardship activities will provide youth with hands-on experiences to learn about the natural environment from both traditional and western scientific perspectives. They also develop a strong sense of place by experiencing the land and ocean daily. Youth want to acquire these skills through experiencing the land and ocean first hand. Youth gain these skills and knowledge through experiencing the land and ocean first-hand and learning from their family and elders. The environmental stewardship programs that provide them with hands-on experiences mainly in the outdoors. Therefore, we proposed Hypothesis 1: Experiential Learning positively relates to Ocean Stewardship.

\subsection{Pro-Environmental Behavior Intention}

Three general sets of environmental beliefs play crucial environmental issues: 1) Nature is a limited resource upon which humans rely; 2) Nature is balanced, highly interdependent and complex, and therefore susceptible to human interference; and 3) Materialism and lack of contact with nature have led our society to devalue life. Pro-environmental behavior intentions are causally related to the personal norm that, in turn, is causally associated with ascribed responsibility and awareness of the different types of environmental consequences. Gadenne, Kennedy, and McKeiver (2009) indicated individual behaviors could ameliorate or exacerbate ecological problems.

"To do what is right to help protect the environment in general daily practice" (Cottrell, 2003). Pro-environmental behavior can define as the action of an individual or group that advocates the sustainable or diminished use of natural resources (Sivek \& Hungerford, 1990). Environmental concern or awareness of consequences has significant effects on pro-environmental behavior or pro-environmental behavioral intent. Disciplines share an interest in understanding internal and external influences on behavior. First altruistic, motivation ranks second, and an egoistic motivation ranks third (Clark, Kotchen, \& Moore, 2003). Behavioral intention is the best predictor of future behavior and that three components determine this intention: 1) a person's global evaluation of performing the behavior (attitude toward the behavior), 2) the perceived social pressure to deliver the behavior (subjective norm), and 3) the person's conviction about whether the required skills and resources to perform the behavior are at one's disposal 
(perceived behavioral control or $\mathrm{PBC}$; for a more extensive presentation of the theory (Ajzen, 1985)).

H2: Experiential Learning is positive relate to Pro-Environmental Behavior Intention.

A goal of the environmental program is to increase the conceptual understanding of the ocean and that participants will be able to engage in socio-scientific dilemmas related to the ocean environment reasonably. Getting involved in oceans stewardship activities will provide youth with hands-on experiences to learn about the natural environment from both traditional and western scientific perspectives.

H3: Ocean Stewardship is positive relate to Pro-Environmental Behavior Intention.

It may be that attitudes formed through a direct environmental experience such as oceanography camps are better predictors of behavior (Bixler \& Floyd, 1997). Stewardship is essential for protecting, preserving, and restoring the environment. Stewardship of the sea lagged far behind even the lax stewardship of the land and that the marine world was degrading more rapidly as pollution and overfishing overwhelm the coast. Society should improve ocean park stewardship and contribute to sustainable communities and ecosystems with parks as part of them (Davis, 2004).

H4: Experiential Learning is positive relate to Pro-Environmental Behavior Intention and Ocean Stewardship as mediation.

\section{Methodology}

The purpose of this study is to determine the extent to which the relationship between the learning experience of the marine stewardship and pro-environmental behavior intention among students and the general public who are in Taiwan and Indonesia. There are several stages to organize in this study, including framework, procedure, time and place, the data collection, participant, measurement, explanation of each variable, demographic question, and data analysis (Figure 2).

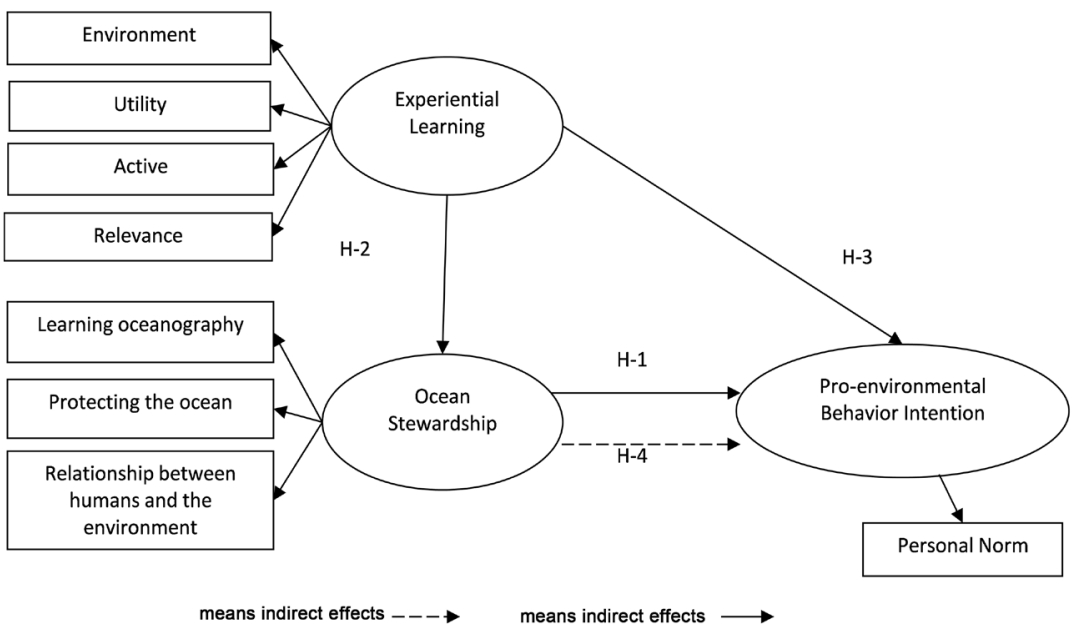

Figure 2. Research framework. 


\subsection{Framework}

See Figure 2.

\subsection{Procedure}

The research is conducted as a quantitative study using survey methods. The data collection is by using a paper-based questionnaire and distributed to students and citizens in Indonesia and Taiwan. In this study, participants only took 15 minutes to complete the survey provided and fill out the survey by way of tick in the column provided. Personal data of participants is kept confidential and used as a control variable. In the questionnaire, there are four parts. The first past is gratitude to the participants about their willingness to fill out the investigation held by the author. The second part is experiential learning consists of 28 statements and used 7 Likert scales. The third part is about ocean stewardship that consists of 20 questions, and the last part is pro-environmental behavior intention that includes nine questions and also contained demographic questions composed of 8 questions relating to demographic information.

\subsection{Bootstrapping}

When doing the moderation effect analysis, the $\mathrm{X}$ and $\mathrm{Z}$ should be standardized first to avoid the collinear problem. The extensive use of casual steps approaches popularized by Baron and Kenny (1986). The approach requires to estimate each path in the model and ascertain whether a variable function as a mediator to evaluate by seeing if specific statistical criteria. The method is used over ten thousand times in international journals. However, more and more research critiqued the causal steps approach is among the lowest in power (Fritz \& MacKinnon, 2007).

The Sobel test (Sobel, 1982) is frequently used as a supplement to test the mediation from the ratio of the standard error of ab. However, the Sobel test requires the assumption that the sampling distribution of the indirect effect is normal. But the sampling distribution of ab tends to be asymmetric, with non zero skewness and kurtosis (Bollen \& Stine, 1990). Mackinnon (2008) and Hayes (2009) suggests the alternative ways of testing mediation are bootstrapping and empirical M-test.

\subsection{Data Collection}

This study used primary data collected through questionnaires conducted in paper-based either in Indonesia or in Taiwan. In this study, the researcher used three languages: Indonesian, English, and Chinese languages. English is the main item on the pooling and analyzing data from both regions.

\subsection{Participant}

The researcher collected 767 participants from Taiwan and Indonesia sample. 
191 students in the Taiwanese experiential group; 240 participants in the Indonesia experiential group; 186 participants in the Taiwan control group; 150 participants in the Indonesia control group (Table 1).

\subsection{Measurement}

This study has three variables. Each variable has a different factor. The first variable is experiential learning, which has four factors that influence the variable. The second factor is ocean stewardship consisting of three factors, while for variable pro-environment behavior intention uses one factor. This is supported by marine awareness of consequences because awareness consequence has an active role in the implementation of pro-environmental behavior intention.

\subsubsection{Experiential Learning}

This research used the questionnaire belonging to (Clem et al., 2014), which originally consisted of 31 questions and leaving 28 questions related to experiential learning. Experiential learning has four factors that influence, and the author used all the questions that might have put on 7 Likert scales. Ranging from strongly disagree to agree strongly. The factor first "environment" consists of 5 questions. The "Active" factor has seven questions investigating the activity of the student. The third-factor "relevance" there are nine questions, while the last factor "utility" uses seven questions relating to the utility for students in the future. The four factors coefficients of Cronbach are 0.92, 0.92, 0.95, 0.94 .

\subsubsection{Ocean Stewardship}

Ocean Stewardship revised from Greely (2008) research that there are 44 items in three factors. The first factor is "learning oceanography," which used the Likert scale as the indicators consisting of 6 questions, and the second factor is "protecting the ocean" used Cudaback (2006) with six questions. The third-factor "relationship between humans and the environment" used Dunlap et al. (2000) with questions and questions in Ocean Stewardship. The author deleted-questions $30,36,38,39,40,42$, and 44 , which was too specific to the ocean terminology. The three factors coefficients of Cronbach are $0.91,0.88$, and 0.76 .

\subsubsection{Pro-Environmental Behavior Intention}

Consists of 3 questions in the questionnaire about pro-environmental behavior intention belonging to (Stern, Dietz, \& Kalof, 1993). The questionnaire section questions how the attitudes and actions of people are to build a sense of pro-environmental behavior intention. The coefficient of Cronbach alpha for pro-environmental behavior intention is 0.754 .

Table 1. The number of participants.

\begin{tabular}{|c|c|c|c|}
\hline & \multicolumn{2}{|c|}{ Regions } & \multirow{2}{*}{ Total } \\
\hline & Taiwan & Indonesia & \\
\hline Control Group & 186 & 150 & 336 \\
\hline Experiment Group & 191 & 240 & 431 \\
\hline Total & 377 & 390 & 767 \\
\hline
\end{tabular}




\section{Result}

In this questionnaire, there are eight demographic questions, including the name of the school, grade, age, gender, nationality, the area of residence, swimming ability, and marine experience as experienced by the participants. Participants in Taiwan are $49.2 \%$ and Indonesia 50.8\%. Junior high school 238 students (31.0\%), senior high school 200 students (26.1\%), university 235 students (undergraduate and master students) (30.6\%) and society 94 people (12.3\%). Participants from Taiwan, junior high school 98 students (26.0\%), senior high school 96 students (25.5\%), University 92 students (24.4\%), and society 91 people (24.1\%). From Indonesia, junior high school 140 students (35.9\%), senior high school 104 students $(26.7 \%)$, university 143 students $(36.7 \%)$ and society 3 people $(0.8 \%)$.

The participants in this research have different swimming abilities. Participants who cannot swim are the most common ones, 213 participants (27.8\%). 134 participants $(34.4 \%)$, and from Taiwan 79 participants (21\%) can't swim. There are 148 participants (19.3\%), including Taiwan 42 participants (11.1\%) and Indonesia 106 participants (27.2\%) can swim less than 15 meters. For 15 - 25 meters, there are 101 participants (13.2\%) divided Taiwan 55 participants (14.6\%) and Indonesia 46 participants (11.8\%) 69 participants (9\%) can swim around 26-50 meters, in Indonesia only 21 participants (5.4\%) but for Taiwan, there are 48 participants (12.7\%) who can swim that distance. 51-100 meters, people who can swim are 50 participants (6.5\%). From Taiwan, 28 participants (7.4\%) and Indonesia 22 participants (5.6\%). In unpredictable participants who can swim over 100 meters, there are 184 participants (24\%), and most of them from Taiwan 123 participants (32.6\%) and Indonesia only 61 participants (15.6\%). Also, two participants didn't want to choose $(0.3 \%)$.

\subsection{Descriptive of Every Factors}

Beside the rank of item in every variable, this research also has the rank of every factor in every variable. Same like when the researcher analysis item in two regions, both of them has different rank of every factor in experiential learning. If the researcher combined both regions, environment is the highest one from experiential learning $(M=5.36, S D=1.33)$, in had same result in Indonesia ( $M$ $=5.77, \mathrm{SD}=1.28$ ) but for Taiwan, the result had different result, in Taiwan utility is the highest one from the experiential learning $(M=5.10, S D=1.17)$. Therefore, the lowest one of Indonesia and Taiwan had the same result. The active factor is the lowest one for both regions $(M=5.08, S D=1.28)$ and Indonesia ( $M$ $=5.29, \mathrm{SD}=1.36)$ and Taiwan $(\mathrm{M}=4.86, \mathrm{SD}=1.15)$ (Table 2).

Ocean stewardship has three factors: learning oceanography, protect the ocean and human environment. Nevertheless, after has data from both regions, the rank of every region has different for the highest one but had the same for the lowest one. After the researchers analysis the combine data, the result showed that relationship between human and environment was the highest one $(\mathrm{M}=3.79, \mathrm{SD}=0.66)$ 
Table 2. Rank of variable of experiential learning.

\begin{tabular}{ccccc}
\hline Regions & Factors & Rank & Mean & SD \\
\hline \multirow{3}{*}{ Combine } & Environment & 1 & 5.36 & 1.33 \\
& Relevance & 2 & 5.31 & 1.25 \\
& Utility & 3 & 5.29 & 1.21 \\
& Active & 4 & 5.08 & 1.27 \\
\hline \multirow{2}{*}{ Taiwan } & Utility & 1 & 5.10 & 1.17 \\
& Environment & 2 & 4.93 & 1.24 \\
& Relevance & 3 & 4.91 & 0.97 \\
& Active & 4 & 4.86 & 1.15 \\
& Environment & 1 & 5.77 & 1.28 \\
& Relevance & 2 & 5.69 & 1.36 \\
& Utility & 3 & 5.48 & 1.23 \\
& Active & 4 & 5.29 & 1.35 \\
\hline
\end{tabular}

same with Taiwan $(\mathrm{M}=3.73, \mathrm{SD}=0.65)$ but the result for Indonesia had different rank for the highest one. In Indonesia Learning oceanography is the highest one $(\mathrm{M}=3.92, \mathrm{SD}=0.84)$. The lowest one of ocean stewardship rank is protect the ocean, for Indonesia $(M=3.7, S D=0.98)$, Taiwan $(M=3.86, S D=0.67)$ and combine these regions $(\mathrm{M}=3.79, \mathrm{SD}=0.66)$. All of them were same for the lowest factor of ocean stewardship (Table 3 ).

\subsection{T-Test of Variables}

The t-test shows that the means for experiential learning and ocean stewardship for Indonesia is higher than Taiwan, but proenvironmental behavior intention is lower than Taiwan sample. Compare with two samples, this research found that Taiwanese proenvironmental behavior intention is significantly higher than Indonesian (Table 4).

\subsection{The Correlation of Factor and Variable}

The result shows that all variable and factor has significant and has relationship between one to each other. For Experiential learning to ocean stewardship has significant relationship $(\mathrm{M}=3.72, \mathrm{SD}=0.67)$, it means between experiential learning and ocean stewardship has positive linier relationship. But we can see the relationship between experiential learning and one of the factor active. They have positive relationship, and the value 0.93 . It means that both of them has strong relationship in this research, both of them has linier relationship. It means that if student can increase their active, they also can increase their experiential learning in their daily life. You can see the correlation value for all variable and all factor in Table 5. 
Table 3. Rank of variable of ocean stewardship.

\begin{tabular}{ccccc}
\hline \multirow{2}{*}{ Regions } & Factors & Rank & Mean & SD \\
\hline \multirow{2}{*}{ Combine } & Human Environment & 1 & 3.79 & 0.66 \\
& Learning Oceanography & 2 & 3.77 & 0.78 \\
& Protect the Ocean & 3 & 3.60 & 0.84 \\
\hline \multirow{2}{*}{ Taiwan } & Human Environment & 1 & 3.73 & 0.64 \\
& Learning Oceanography & 2 & 3.62 & 0.69 \\
& Protect the Ocean & 3 & 3.49 & 0.65 \\
\hline \multirow{2}{*}{ Indonesia } & Learning Oceanography & 1 & 3.92 & 0.84 \\
& Human Environment & 2 & 3.85 & 0.67 \\
& Protect the Ocean & 3 & 3.71 & 0.97 \\
\hline
\end{tabular}

Table 4. T-test of regions.

\begin{tabular}{|c|c|c|c|c|c|c|c|c|}
\hline & Regions & $\mathbf{N}$ & Mean & $\mathrm{SD}$ & $\mathbf{t}$ & df & Sig(2-tailed) & Mean difference \\
\hline \multirow{3}{*}{ EL } & Taiwan & 377 & 4.95 & 1.03 & \multirow{3}{*}{-7.37} & \multirow{3}{*}{765} & \multirow{3}{*}{0.000} & \multirow{3}{*}{-0.60} \\
\hline & & & & & & & & \\
\hline & Indonesia & 390 & 5.55 & 1.21 & & & & \\
\hline \multirow[b]{2}{*}{ OS } & Taiwan & 377 & 3.61 & 0.57 & \multirow[b]{2}{*}{-4.45} & \multirow[b]{2}{*}{765} & \multirow[b]{2}{*}{0.000} & \multirow[b]{2}{*}{-0.21} \\
\hline & Indonesia & 390 & 3.83 & 0.73 & & & & \\
\hline \multirow[b]{2}{*}{ PBI } & Taiwan & 377 & 3.76 & 0.54 & \multirow[b]{2}{*}{3.02} & \multirow[b]{2}{*}{765} & \multirow[b]{2}{*}{0.003} & \multirow[b]{2}{*}{0.13} \\
\hline & Indonesia & 390 & 3.63 & 0.65 & & & & \\
\hline
\end{tabular}

Table 5. Correlation between variables and factors.

\begin{tabular}{|c|c|c|c|c|c|c|c|c|c|c|}
\hline Variable & (1) & (2) & (3) & (4) & (5) & (6) & (7) & (8) & (9) & (10) \\
\hline (1) & 1 & $0.72^{* *}$ & $0.48^{* *}$ & $0.85^{* *}$ & $0.93^{* *}$ & $0.95^{* *}$ & $0.93^{* *}$ & $0.69^{* *}$ & $0.66^{* *}$ & $0.53^{* *}$ \\
\hline (2) & & 1 & $0.55^{\star *}$ & $0.57^{\star \star}$ & $0.67^{\star *}$ & $0.71^{\star *}$ & $0.68^{* *}$ & $0.86^{\star *}$ & $0.89^{* *}$ & $0.84^{\star *}$ \\
\hline (3) & & & 1 & $0.38^{* *}$ & $0.43^{* *}$ & $0.46^{* *}$ & $0.48^{* *}$ & $0.52^{* *}$ & $0.48^{\star *}$ & $0.44^{\star *}$ \\
\hline (4) & & & & 1 & $0.78^{\star *}$ & $0.72^{* *}$ & $0.74^{* *}$ & $0.54^{* *}$ & $0.50^{* *}$ & $0.44^{\star *}$ \\
\hline (5) & & & & & 1 & $0.87^{\star *}$ & $0.80^{* *}$ & $0.65^{\star *}$ & $0.62^{* *}$ & $0.49^{* *}$ \\
\hline (6) & & & & & & 1 & $0.86^{* *}$ & $0.67^{\star *}$ & $0.66^{* *}$ & $0.52^{\star *}$ \\
\hline (7) & & & & & & & 1 & $0.67^{\star *}$ & $0.63^{\star *}$ & $0.49^{\star *}$ \\
\hline (8) & & & & & & & & 1 & $0.73^{\star *}$ & $0.56^{\star *}$ \\
\hline (9) & & & & & & & & & 1 & $0.60^{\star *}$ \\
\hline (10) & & & & & & & & & & 1 \\
\hline $\mathbf{N}$ & 767 & 767 & 767 & 767 & 767 & 767 & 767 & 767 & 767 & 767 \\
\hline Mean & 5.24 & 3.79 & 3.77 & 5.35 & 5.29 & 5.07 & 5.30 & 3.93 & 3.64 & 3.79 \\
\hline SD & 1.17 & 0.64 & 0.81 & 1.33 & 1.21 & 1.27 & 1.24 & 0.73 & 0.84 & 0.67 \\
\hline
\end{tabular}

Note: (1) Experiential learning, (2) Ocean stewardship, (3) Proenvironmental behavior intention, (4) Environment, (5) Utility, (6) Active, (7) Relevance, (8) Learning Oceanography, (9) Protect the Ocean, (10) Relationship between human and environment. 
Experiential learning has a positive effect on pro-environmental behavior intention ( $\mathrm{B}=0.23, p<0.001)$. It means when people act to do experiential learning, their pro-environmental behavior will increase. Experiential learning has a positive relationship to ocean stewardship $(\mathrm{B}=0.41, p<0.001)$. Ocean stewardship has a positive relation to pro-environmental behavior intention $(\mathrm{B}=0.61, p$ $<0.001)$. For ocean stewardship, the relationship between experiential learning to pro-environmental behavior intention is still significant $(\mathrm{B}=0.07, p<0.01)$. The coefficient decreases from $B=0.23$ to $B=0.07$. It means that ocean stewardship mediates for the relationship between experiential learning and proenvironmental behavior intention. Experiential learning has a positive relationship to pro-environmental behavior and uses ocean stewardship as partial mediation (Table 6).

\subsection{Compare to the Cross Nation's Effects}

The cross nations (NAT) effects used SEM (structure equation model) to detect the moderation effects of ocean stewardship (OS) and experiential learning (EL) to proenvironmental behavior intention (PBI). Figure 3 shows the results of NAT

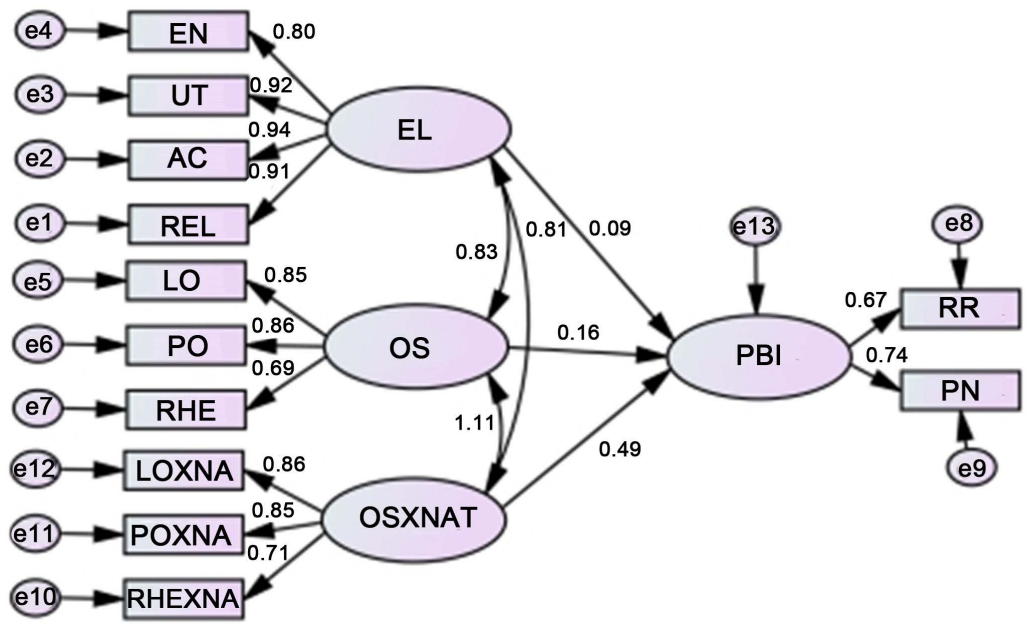

Figure 3. The moderation model of NAT and OS to PBI.

Table 6. Regression of variables.

\begin{tabular}{ccccc}
\hline & $\begin{array}{c}\text { EL => PBI } \\
\text { B (BETA) }\end{array}$ & $\begin{array}{c}\text { EL }=>\text { OS } \\
\text { B (BETA) }\end{array}$ & $\begin{array}{c}\text { OS }=>\text { PBI } \\
\text { B (BETA) }\end{array}$ & $\begin{array}{c}\text { EL = OS }=>\text { PBI } \\
\text { B (BETA) }\end{array}$ \\
\hline $\begin{array}{c}\text { Intercept } \\
\text { Control Variable }\end{array}$ & $2.37^{* * *}$ & $1.43^{* * *}$ & $1.64^{* * *}$ & $1.67^{* * *}$ \\
Grade & $0.01(0.07)^{*}$ & $0.01(0.06)^{* *}$ & $0.01(0.04)$ & $-0.04(-0.03)$ \\
Swimming ability & $-0.05(-0.13)^{* * *}$ & $0.01(0.04)$ & $-0.05(-0.15)^{* * *}$ & $-0.06(-0.16)$ \\
Experiential Learning & $0.23(0.44)^{* * *}$ & $0.412(0.71)^{* * *}$ & & $0.07(0.12)^{* *}$ \\
Ocean Stewardship & & & $0.61(0.56)^{* * *}$ & $0.52(0.48)^{* * *}$ \\
$\mathrm{R}^{2}$ & 0.23 & 0.55 & 0.33 & 0.33 \\
F-Value & 77.127 & 314.021 & 126.76 & 97.08 \\
Sig & 0.000 & 0.000 & 0.000 & 0.000 \\
\hline
\end{tabular}


moderate the relationship between OS and PBI. The significant positive moderation effect of NAT to the relationship between OS and PBI $(\mathrm{B}=0.49, p<0.05)$ means the relationship of OS and PBI in Taiwan $(\mathrm{NAT}=1)$ is higher than Indonesia (NAT $=0$ ). However, the moderation effect of NAT and EL to PBI has the oppositive result. Figure 4 The significant negative moderation of NAT to the relationship between EL and PBI $(B=-0.34, p<0.05)$ means the relationship of EL and PBI in Taiwan is lower than Indonesia.

\section{Discussion}

\subsection{Experiential Learning Can Significantly Contribute to Ocean Stewardship}

Indonesia's regression value in this hypothesis is higher than Taiwan, even with these regions using the same control variable. Both of these regions have significant value. The $\mathrm{R}^{2}$ of the hypothesis in Taiwan is 0.395 , and the F-value is 81.179. It is lower than the Indonesia result. It means, according to $\mathrm{R}^{2}$ in Taiwan, that experiential learning can enhance people's ocean stewardship 39.5\%, and $60.5 \%$ is affected by grade and swimming ability. For F-value, it means that experiential learning and the control variable can contribute to ocean stewardship because the F-value in Taiwan is significant. In Indonesia, the $\mathrm{R}^{2}$ of hypothesis 1 is 0.653 ; it means that $65.3 \%$ of people's experiential learning can increase their ocean stewardship, and $34.7 \%$ of their grade and swimming ability also can increase their ocean stewardship. The F-value in Indonesia is 242.162; It means that experiential learning is significantly enhancing and contributing to ocean stewardship if people do it. It says that Indonesia has a better relationship between experiential learning to ocean stewardship. And it will have an impact on ocean stewardship of people if the teacher or coach asks participants to do and experience it to understand it.

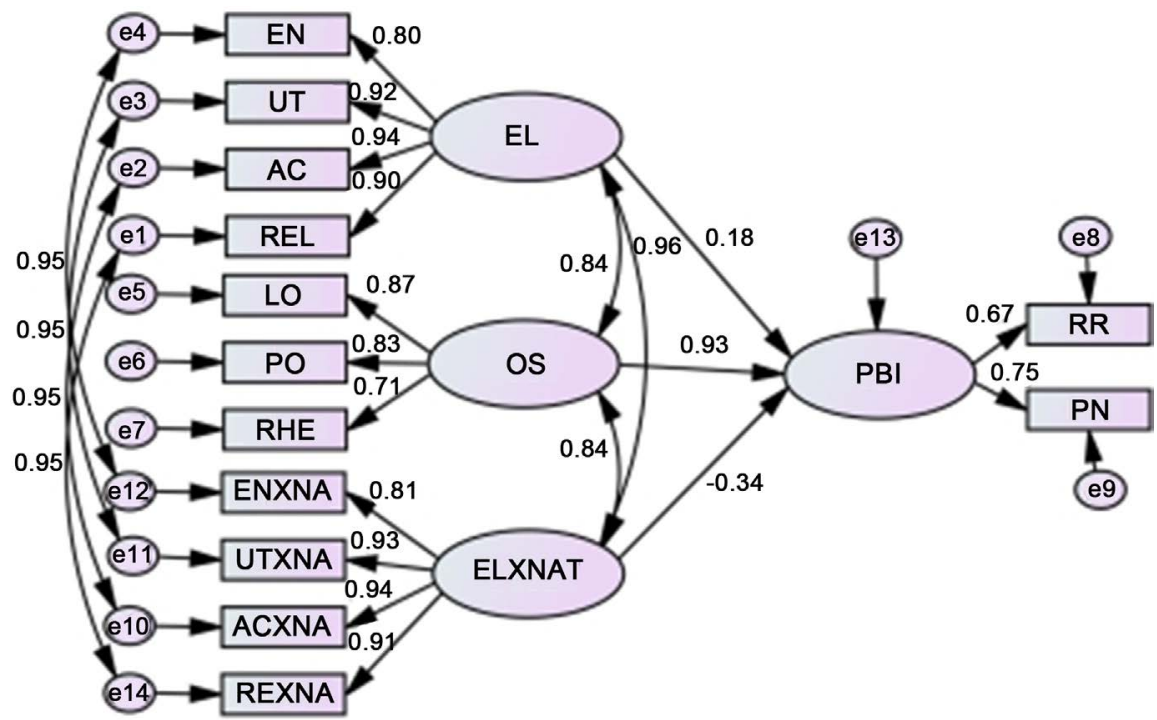

Figure 4. The moderation model of NAT and EL to PBI. 


\subsection{Experiential Learning Contributes to Pro-Environmental Behavior Intention}

The second hypothesis of this result showed that it is accepted and has positively related to experiential learning and pro-environmental behavior intention. The coefficient of experiential learning in Taiwan is 0.196 , and it is significant but lower than the Indonesia coefficient experiential learning $(B=0.359)$. The $R^{2}$ of the hypothesis in Taiwan is 0.147 ; it means that $14.7 \%$ of people experiential learning can affect people's pro-environmental behavior intention, and they should care about their grade and their swimming ability. Because in this research, the researcher found that $85.3 \%$ of experiential learning is also affected by their grade and their swimming ability. This is different from Indonesia, in Indonesia, the $\mathrm{R}^{2}$ is 0.307 .

It means that the percentage of experiential learning effect to pro-environmental behavior intention is higher than in Taiwan. 30.7\% of experiential learning in Indonesia can affect people's pro-environmental behavior intentions in Indonesia. For the F-value in Indonesia is 56.962, it means that experiential learning can contribute to pro-environmental behavior intention and use the control variable (grade and swimming ability) to enhance people's in Indonesia. And it is higher than in Taiwan. The researcher found that Taiwan F-Value is 21.435.

\subsection{Ocean Stewardship Affected to Pro-Environmental Behavior Intention}

The third hypothesis in this research is ocean stewardship to pro-environmental behavior intention. The result showed that ocean stewardship and pro-environmental behavior intention has a positive relationship. Besides the different coefficient of ocean stewardship, Indonesia and Taiwan also have a difference in $\mathrm{R}^{2}$ and F-value. $\mathrm{R}^{2}$ value in Taiwan is 0.226 ; it means that $22.6 \%$ of ocean stewardship can impact pro-environmental behavior intention, and $77.4 \%$ is from the control group (grade and swimming ability). In Indonesia $\mathrm{R}^{2}$ value is 0.422 . It means that $42.2 \%$ of ocean stewardship can affect people in Indonesia, but $57.8 \%$ is affected by swimming ability and also grade. The F-value in Taiwan is 36.216 . It means that ocean stewardship can contribute to weak environmental behavior intention and that $\mathrm{F}$ value in Taiwan is higher than in Indonesia (93.806).

\subsection{Experiential Learning Enhances Pro-Environmental Behavior Intention and Ocean Stewardship as Mediation}

In Taiwan, the value of the relationship is significant, and also, the coefficient of experiential learning decreases from 0.196 to 0.075 . The experiential learning coefficient in Indonesia decreased from 0.359 to 0.04 . The $\mathrm{R}^{2}$ value is 0.238 for Taiwan. It means that $23.8 \%$ of experiential learning can affect pro-environmental behavior intention, even using ocean stewardship as mediation. And $76.2 \%$ of others affected by grade and swimming ability. In Indonesia, the $\mathrm{R}^{2}$ value is 0.423 . It means that $42.3 \%$ of experiential learning can change pro-environmental behavior intention using ocean stewardship as mediation. The F-value of experien- 
tial learning is 70.509 for Indonesia. Experiential learning can contribute to pro-environmental behavior intention, and it is higher than Taiwan's F-value.

\subsection{Temporary Experiential Learning Also Enhance Pro-Environmental Behavior Intention}

Indonesia Experiential learning is higher than in Taiwan. The average of experiential learning from Indonesia is 0.6 higher than in Taiwan. But for pro-environmental behavior intention, Taiwan is 0.13 higher than Indonesia. It is a common situation, as Kollmuss and Agyeman (2002) reported that "everyone who tries to change a habit needs a long time, because it is so difficult, even when that people know that a new behavior will give them more advantages." This result is also supported that temporal discrepancy refers to the fact that people's attitudes change over time. It means that people will change their behavior temporarily, depends on what kind of experience they get and what knowledge they gain.

\section{Conclusion}

The motivation of this research is to clarify the relationship among ocean stewardship and people's pro-environmental behavior intention to their environment. The researcher identified experiential learning has a positive relationship to ocean stewardship and pro-environmental intention. The results supported by Beavis (1994), stewardship tends to be a specific place, and education is needed in stewardship because it can understand complex issues, critically analyze problems, develop solutions, and consider the consequences of actions taken. Attitudes about the environment also link to ecological knowledge, and attitudes that form through direct experience with nature believe to be better predictors of behavior (Pooley \& O'Connor, 2000). Learning is only in terms of observable behavior, that environment shapes behavior, and time reinforces the behavior (Bredo, 1997; Fenwick, 2000).

The hypothesis for ocean stewardship to pro-environmental behavior intention support both in Indonesia and Taiwan. All factors in ocean stewardship have a significant correlation to pro-environmental behavior intention. The ocean stewardship is positively related to pro-environmental behavior intention in both Taiwan and Indonesia. It is supported by Schlag (2004) Involvement in ocean stewardship activities will help youth learn about the ecology of the environment, traditional knowledge, and it will increase their awareness of the governance functions of co-management bodies. Experiential learning to pro-environmental behavior intention is positively related even using ocean stewardship as the mediation has supported this but only in Taiwan. This hypothesis has not endorsed in Indonesia. In Taiwan, the value of the relationship is significant and also has the coefficient of experiential learning decreasing from 0.19 to 0.07 . The experiential learning coefficient in Indonesia is decreasing from 0.35 to 0.04 . Indonesia still doesn't have marine education to promote its understanding of ocean stewardship. Increasing pro-environmental behavior intention is not enough if only asking the student to do experiential learning. 


\section{Future Research}

This study proposes some suggestions for future research about the problem of experiential learning, ocean stewardship, and pro-environmental behavior:

1) Anticipate the required time to conduct large scale overseas surveys.

2) Take more time to anticipate cultural differences when conducting research overseas.

3) Give more attention to analyze data, decreasing the error when analyzing data collected in different languages.

4) Give attention to teach ocean stewardship to students and citizens.

5) Provide more research for ocean stewardship and pro-environmental behavior intention.

\section{Conflicts of Interest}

The authors declare no conflicts of interest regarding the publication of this paper.

\section{References}

Ajzen, I. (1985). From Intentions to Actions: A Theory of Planned Behavior. In Action Control (pp. 11-39). Berlin: Springer. https://doi.org/10.1007/978-3-642-69746-3_2

Baron, R. M., \& Kenny, D. A. (1986). The Moderator-Mediator Variable Distinction in Social Psychological Research: Conceptual, Strategic and Statistical Considerations. Journal of Personality and Social Psychology, 51, 1173-1182. https://doi.org/10.1037/0022-3514.51.6.1173

Beavis, M. A. (1994). Environmental Stewardship in History, Theory, and Practice. Winnipeg: Workshop Proceedings, Institute of Urban Studies, University of Winnipeg.

Bixler, R. D., \& Floyd, M. F. (1997). Nature Is Scary, Disgusting, and Uncomfortable. Environment and Behavior, 29, 443-467. https://doi.org/10.1177/001391659702900401

Bollen, K. A., \& Stine, R. (1990). Direct and Indirect Effects: Classical and Bootstrap Estimates of Variability. Sociological Methodology, 20, 115-140.

https://doi.org/10.2307/271084

Bredo, E. (1997). The Social Construction of Learning. In Handbook of Academic Learning: Construction of Knowledge (pp. 3-45). San Diego, CA: Academic Press. https://doi.org/10.1016/B978-012554255-5/50002-8

Burns, H. L., \& Briley, J. (2015). Going Deep: Reflections on Teaching Deep Ecology in Costa Rica. Transformative Dialogues: Teaching and Learning Journal, 8, 1-14.

Carpini, M. X. D., \& Keeter, S. (1996). What Americans Know about Politics and Why It Matters. New Haven, CT: Yale University Press.

Clark, C. F., Kotchen, M. J., \& Moore, M. R. (2003). Internal and External Influences on Pro-Environmental Behavior: Participation in a Green Electricity Program. Journal of Environmental Psychology, 23, 237-246. https://doi.org/10.1016/S0272-4944(02)00105-6

Clem, J. M., Mennicke, A. M., \& Beasley, C. (2014). Development and Validation of the Experiential Learning Survey. Journal of Social Work Education, 50, 490-506. https://doi.org/10.1080/10437797.2014.917900

Cottrell, S. P. (2003). Influence of Sociodemographics and Environmental Attitudes on General Responsible Environmental Behavior among Recreational Boaters. Environ- 
ment and Behavior, 35, 347-375. https://doi.org/10.1177/0013916503035003003

Cudaback, C. (2006). What Do College Students Know about the Ocean? Eos, Transactions American Geophysical Union, 87, 418-421.

https://doi.org/10.1029/2006EO400003

Daigle, D. (2003). Dead Seas; Nutrient Pollution in Coastal Waters. Multinational Monitor, 24, 12 .

Davis, G. E. (2004). Maintaining Unimpaired Ocean Resources and Experiences: A National Park Service Ocean Stewardship Strategy. The George Wright Forum, 21, 22-41.

Dube, C. (2009). Assessment and Evaluation Practices in Outdoor, Experiential, Environmentally-Focused Integrated and Interdisciplinary Programs.

Dunlap, R. E., Van Liere, K. D., Mertig, A. G., \& Jones, R. E. (2000). New Trends in Measuring Environmental Attitudes: Measuring Endorsement of the New Ecological Paradigm: A Revised NEP Scale. Journal of Social Issues, 56, 425-442. https://doi.org/10.1111/0022-4537.00176

Enos, R. M. (2012). Beef Production from Conception to Consumption: An Innovative Experiential Learning Program. Alpine, TX: Sul Ross State University.

Fenwick, T. J. (2000). Expanding Conceptions of Experiential Learning: A Review of the Five Contemporary Perspectives on Cognition. Adult Education Quarterly, 50, 243-272. https://doi.org/10.1177/07417130022087035

Fritz, M. S., \& MacKinnon, D. P. (2007). Required Sample Size to Detect the Mediated Effect. Psychology Science, 18, 233-239. https://doi.org/10.1111/j.1467-9280.2007.01882.x

Fujii, S. (2006). Environmental Concern, Attitude toward Frugality, and Ease of Behavior as Determinants of Pro-Environmental Behavior Intentions. Journal of Environmental Psychology, 26, 262-268. https://doi.org/10.1016/j.jenvp.2006.09.003

Gadenne, D. L., Kennedy, J., \& McKeiver, C. (2009). An Empirical Study of Environmental Awareness and Practices in SMEs. Journal of Business Ethics, 84, 45-63. https://doi.org/10.1007/s10551-008-9672-9

Greely, T. (2008). Ocean Literacy and Reasoning about Ocean Issues: The Influence of Content, Experience, and Morality. Tampa, FL: University of South Florida.

Guest, H., Lotze, H. K., \& Wallace, D. (2015). Youth and the Sea: Ocean Literacy in Nova Scotia, Canada. Marine Policy, 58, 98-107. https://doi.org/10.1016/j.marpol.2015.04.007

Hayes, A. F. (2009). Beyond Baron and Kenny: Statistical Mediation in the New Millennium. Communication Monographs, 76, 408-420. https://doi.org/10.1080/03637750903310360

Kolb, A. Y., \& Kolb, D. A. (2005). Learning Styles and Learning Spaces: Enhancing Experiential Learning in Higher Education. Academy of Management Learning \& Education, 4, 193-212. https://doi.org/10.5465/amle.2005.17268566

Kolb, D. (1984). Experiential Education: Experience as the Source of Learning and Development. Englewood Cliffs, NJ: Prentice Hall.

Kolb, D. A. (2014). Experiential Learning: Experience as the Source of Learning and Development. Upper Saddle River, NJ: FT Press.

Kollmuss, A., \& Agyeman, J. (2002). Mind the Gap: Why Do People Act Environmentally and What Are the Barriers to Pro-Environmental Behavior? Environmental Education Research, 8, 239-260. https://doi.org/10.1080/13504620220145401

MacKinnon, D. P. (2008). Introduction to Statistical Mediation Analysis. Mahwah, NJ: Lawrence Erlbaum Associates. 
NMEA (2010). The Ocean Literacy Campaign Special Report \#3, Featuring: Ocean Literacy Scope and Sequence for Grades K-12. College Park, MD: National Marine Educators Association.

Obama, B. (2010). Executive Order 13547: Stewardship of the Ocean, Our Coasts, and the Great Lakes. Washington DC: White House, Office of the Press.

Pooley, J. A., \& O'Connor, M. (2000). Environmental Education and Attitudes: Emotions and Beliefs Are What Is Needed. Environment and Behavior, 32, 711-723. https://doi.org/10.1177/0013916500325007

Schlag, M. (2004). Engaging Inuvialuit Youth in Oceans Stewardship: A Proposed Strategy.

Sivek, D. J., \& Hungerford, H. (1990). Predictors of Responsible Behavior in Members of Three Wisconsin Conservation Organizations. The Journal of Environmental Education, 21, 35-40. https://doi.org/10.1080/00958964.1990.9941929

Smith, P., \& Ford, B. (1995). Project Earth Science: Physical Oceanography. Arlington, VA: NSTA (National Science Teachers Association).

Sobel, M. E. (1982). Asymptotic Intervals for Indirect Effects in Structural Equations Models. In S. Leinhart (Ed.), Sociological Methodology 1982 (pp. 290-312). San Francisco, CA: Jossey-Bass. https://doi.org/10.2307/270723

Steel, B. S., Smith, C., Opsommer, L., Curiel, S., \& Warner-Steel, R. (2005). Public Ocean Literacy in the United States. Ocean \& Coastal Management, 48, 97-114. https://doi.org/10.1016/j.ocecoaman.2005.01.002

Stern, P. C., Dietz, T., \& Kalof, L. (1993). Value Orientations, Gender, and Environmental Concern. Environment and Behavior, 25, 322-348. https://doi.org/10.1177/0013916593255002

Stern, P. C., Dietz, T., Abel, T., Guagnano, G. A., \& Kalof, L. (1999). A Value-Belief-Norm Theory of Support for Social Movements: The Case of Environmentalism. Human Ecology Review, 6, 81-97.

Stern, P. C., Kalof, L., Dietz, T., \& Guagnano, G. A. (1995). Values, Beliefs, and Pro-Environmental Action: Attitude Formation toward Emergent Attitude Objects. Journal of Applied Social Psychology, 25, 1611-1636. https://doi.org/10.1111/j.1559-1816.1995.tb02636.x

Van Dover, C., Aronson, J., Pendleton, L., Smith, S., Arnaud-Haond, S., Moreno-Mateos, D., Danovaro, R. et al. (2014). Ecological Restoration in the Deep Sea: Desiderata. Marine Policy, 44, 98-106. https://doi.org/10.1016/j.marpol.2013.07.006 